Jurnal Konstruksi Hukum | ISSN: XXXX | E-ISSN: XXXX Vol. 1, No. 2, Oktober 2020, Hal. 325-328| Available online at https://www.ejournal.warmadewa.ac.id/index.php/jukonhum DOI: https://doi.org/10.22225/jkh.1.2.2556.325-328

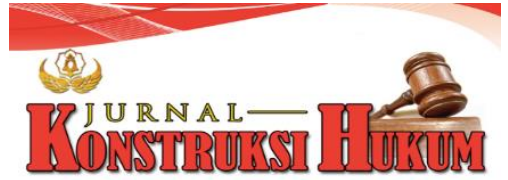

\title{
EFEKTIFITAS PELAKSANAAN PERATURAN DAERAH KABUPATEN BADUNG NOMOR 2 TAHUN 2016 TENTANG SISTEM ONLINE PAJAK DAERAH
}

\author{
I Gusti Ayu Mas Yuni, I Gusti Bagus Suryawan, Luh Putu Suryani \\ Fakultas Hukum Universitas Warmadewa, Denpasar-Bali, Indonesia
}

\begin{abstract}
Abstrak
Badan Pendapatan Daerah/Pasedahan Agung Kabupaten Badung merupakan organisasi perangkat daerah yang memiliki tujuan pokok dan fungsi mengelola pendapatan daerah sebagai sumber pembiayaan daerah dalam melaksanakan pembangunan daerah. Penelitian ini bertujuan untuk menganalisis tata cara pelaksanaan dan mengetahui efektifitas penerapan Peraturan Daerah Kabupaten Badung Nomor 2 Tahun 2016 tentang Sistem Online Pajak Daerah. Penelitian ini menggunakan metode empiris. Ada 2 bentuk data yang digunakan yaitu primer dan sekunder dikumpulkan melalui wawancara. Hasil penelitian menunjukan bahwa tata cara pelaksanaan sistem online pajak daerah wajib pajak melaporkan pajaknya melalu web Badan Pendapatan dan adanya pemasangan alat perekam monitoring transaksi usaha pada wajib pajak. Pelaksanaan Sistem Online Pajak Daerah dapat dikatakan efektif dilihat dari peningkatan pelaporan pajak online dan peningkatan pemasangan alat monitoring transaksi usaha pada wajib pajak dan peningkatan Pajak PAD. Adapun faktor kendala yuridis dan non yuridis yaitu pada wajib pajak yang menolak untuk memasangkan alat perekam monitoring transaksi usaha wajib pajak. Oleh karena itu, melalui penelitian ini, Badan Pendapatan Daerah/Pasedahan diharapkan meningkatkan sosialisasi pemahaman dan mempertegas sanksi dalam Peraturan Daerah Kabupaten Badung Nomor 2 Tahun 2016 tentang Sistem Online Pajak Daerah.
\end{abstract}

Kata Kunci: Pajak Daerah; Perda; Sistem Online

\begin{abstract}
The Regional Revenue Agency/Pasedahan Agung Badung Regency is a regional apparatus organization that has the main objective and function of managing regional revenue as a source of regional financing in implementing regional development. This study aims to analyze the implementation procedures and determine the effectiveness of the implementation of the Badung Regency Regulation Number 2 of 2016 concerning the Local Tax Online System. This study uses an empirical method. There are 2 forms of data used, namely primary and secondary, namely collected through interviews. The results showed that the procedures for implementing the online system of local taxes for taxpayers to report their taxes through the Revenue Agency web and the installation of recording devices for monitoring business transactions on taxpayers. The implementation of the Local Tax Online System can be said to be effective as seen from the increase in online tax reporting and the increase in the installation of business transaction monitoring tools for taxpayers and the increase in PAD Taxes. The juridical and nonjuridical constraints are the taxpayers who refuse to install a recording device for monitoring taxpayers' business transactions. Therefore, through this research, the Regional Revenue / Pasedahan Agency is expected to increase the socialization of understanding and reinforce the sanctions in the Badung Regency Regional Regulation Number 2 of 2016 concerning the Online Regional Tax System.
\end{abstract}

Keywords: Local tax; Perda; Online System

\section{PENDAHULUAN}

Pajak adalah kontribusi wajib pajak kepada Negara yang terutang oleh orang pribadi atau badan yang bersifat memaksa berdasarkan Undang-Undang dengan tidak mendapatkan imbalan secara langsung dan digunakan untuk keperluan Negara bagi sebesar-besarnya kemakmuran rakyat berdasarkan Peraturan UU No. 28 Tahun 2007 tentang Ketentuan Umum dan tata cara perpajakan, pasal 1 ayat 1. Hukum Pajak dapat juga disebut dengan hukum fiskal dan pajak dapat di bagi menjadi 2 pajak pusat dan pajak daerah. Pajak pusat adalah pajak yang dapat ditetapkan oleh pemerintah pusat melalui UU 
yang wewenang pemungutannya ada pada pemerintah pusat dan hasilnya digunakan oleh pengeluaran dan pembangunan pemerintah pusat. Sedangkan Pajak daerah ialah iuran wajib pajak yang dilakukan oleh orang pribadi atau badan bedasarkan peraturan daerah yang wewenang pemungutan dilaksanakan oleh pemerintah daerah dan hasilnya digunakan untuk membiayai pengeluaran daerah dan pembangunan daerah.

Badan Pendapatan Daerah/Pasedahan Agung Kabupaten Badung merupakan organisasi perangkat daerah yang memiliki tujuan pokok dan fungsi mengelola pendapatan daerah sebagai sumber pembiayaan daerah dalam melaksanakan pembangunan daerah. Bahwa pelaksanaan pemungutan pajak daerah yang konvensional dengan memperhatikan teknologi informasi saat ini dan tuntutan peningkatan pelayanan publik maka perlu ditingkatkan melalui sistem elektronik yang merupakan perujutan dari egoverment. Perlu dilakukan peningkatan tata kelola pemungutan pajak daerah sebagai pelaksanaan kewenangan daerah sesuai ketentuan pasal 2 ayat (2) Undang-Undang Nomor 28 Tahun 2009 tentang pajak daerah dan retribusi daerah, dengan melaksanakan Sistem Online Pajak Daerah sehingga dapat memberikan jaminan kepastian hukum dan adanya transparasi dalam pemungutan pajak daerah. Dengan ini Peraturan Daerah Kabupaten Badung mengeluarkan Peraturan Daerah yang untuk selanjutnya disebut Perda yaitu Perda Nomor 2 Tahun 2016 tentang Sistem Online Pajak Daerah.

Beberapa peneltian terkait dengan sistem perpajakan seperti Leliya \& Afiyah, (2016); Puspitasari \& Sumerthayasa (2017), namun pada penelitian baru ini lebih difokus pada sistem online pajak daerah. Dalam hal ini, Badan Pendapatan Daerah/Pasedahan Agung Kabupaten Badung dalam melaksanakan sistem online pajak daerah hanya dapat dilakukan oleh Wajib Pajak Badan yang sifat pemungutannya bersifat self-assessment system. Self-assessment system adalah wajib pajak menghitung, memperhitungkan, melaporkan dan membayar pajaknya sendiri, jenis pajak yang termasuk dalam jenis ini antara lain Pajak Hotel, Pajak Restoran, Pajak Hiburan, dan Pajak Parkir.

Dengan adanya sistem pajak online dapatnya mempermudah Wajib pajak dalam melaporkan pajaknya tidak perlu datang lagi ke dinas untuk melaporkan pajaknya dan dengan dipasangkannya alat monitoring transaksi usaha pada wajib pada untung mengurangi tingkat kebocoran pada transaksi usaha pada wajib pajak. Dengan demikian wajib pajak dapat melaporkan pajaknya dimana saja dan kapan saja. Sistem ini tentu saja tidak selalu dapat dilaksanakan dengan baik hal ini dikarenakan sistem ini masih baru sehingga masih terdapat kekurangan. Banyaknya juga ketidakmengertian wajib pajak mengenai tata cara penggunaan sistem ini maka perlu diperhatikan kepentingan wajib pajak tersebut dengen memberikan informasi mengenai sistem ini.

Setelah diberlakukannya Perda Nomor 2 Tahun 2016 maka perlu dilakukan evaluasi untuk mengetahui apakah penerapan Perda tersebut dan pelaksanaannya sudah efektif dan hambatanhambatan apa saja yang terjadi ketika sistem online pajak diterapkan khususnya di daerah Kabupaten Badung. Berdasarkan uraian masalah tersebut diatas, maka penelitian baru ini bertujuan untuk mengetahui tata cara pelaksanaan Peraturan Daerah Kabupaten Badung Nomor 2 Tahun 2016 tentang Pelaksanaan Sistem Online Pajak Daerah dan mengetahui efektifitas penerapan Peraturan daerah Kabupaten Badung Nomor 2 Tahun 2016 tentang Pelaksanaan Sistem Online Pajak Daerah.

\section{METODE PENELITIAN}

Penelitian ini adalah penelitian empiris, yaitu tipe penelitian yang berdasarkan pada Peraturan Daerah Kabupaten Badung berdasarkan pada kenyataan penerapannya di lapangan (Bambang, 2009).

Adapun sumber data yang digunakan dalam penelitian ini berasal dari data primer, yaitu data yang diperoleh dari kenyataan di lapangan yaitu di Kantor Pendapatan daerah/Pasedahan Agung Kabupaten Badung yang mempunyai kekuatan mengikat bagi setiap individu atau masyarakat yang berasal dari Peraturan Perundang-undangan. Selanjtunya, bahan hukum sekunder, yaitu bahan hukum yang erat kaitannya dengan bahan hukum primer dan dapat membantu menganalisa, memahami dan menjelaskan bahan hukum primer, antara lain: buku-buku, hasil penelitian sebelumnya, hasil seminar, dan elektronik.

Teknik pengumpulan data dilakukan melalui teknik kepustakaan dan wawancara kepada Pegawai Staff Data dan TI Badan Instansi di Kantor Badan Pendapatan/ Pesedahan Agung Kabupaten Badung. Kemudian, data diolah dan dianalisis dengan menggunakan intepretasi dan argumentasi hukum secara sistematis serta ditaukan secara deskriptif. Selanjutnya diolah dan dianalisis secara kualitatif dimana penelitian ini mengacu pada norma hukum yang terdapat dalam undang-undang yang berkaitan dengan teori-teori hukum yang menjadi objek penelitian (Ali, 2015). 


\section{HASIL DAN PEMBAHASAN}

Pemerintah daerah merupakan daerah otonom yang dapat menjalankan urusan pemerintah dengan seluas-luasnya serta mendapat hak untuk mengatur kewenangan pemerintahan kecuali urusan pemerintahan yang oleh undang-undang ditentukan sebagai urusan pemerintahan pusat (Kaho, 1982). Kepala Daerah sebagai pelaksana roda pemerintahan mempunyai wewenang dan kewajiban tertentu, wewenangnya yaitu Menerbitkan Surat Ketetapan Pajak Daerah, Melakukan Penagihan Pajak, Membetulkan atau membatalkan Surat Ketetapan dan menghapus sanksi administrasi, Melakukan Pemeriksaan terhadap wajib pajak, Melakukan Penyelidikan (Munawir, 1997).

Berdasarkan hasil wawancara yang dilakukan pada tanggal 20 November 2018 dengan Bayu Angga Widura selaku staff bidang Data \& TI Badan Pendapatan Daerah/ Pasedahan Agung Kabupaten Badung dalam melaksanakan urusan Pemerintahan Daerah berdasarkan asas otonomi daerah dan tugas pembantuan dalam menentukan kebijakan di bidang perancangan dan peningkatan Pendapatan Asli Daerah (PAD). Badan Pendapatan Daerah / Pasedahan Agung Kabupaten Badung berinovasi melaksakan Sistem Online Pajak Daerah untuk meningkatkan Pendapatan daerah, Sistem Online Pajak Daerah ada 2 yaitu sistem pelaporan pajak dan sistem alat perekam transaksi usaha pada wajib pajak dengan adanya sistem online pajak daerah dapat mempermudah wajib pajak dalam melaporkan pajaknya dan untuk mengurangi tingkat kebocoran/ kecurangan trransaksi usaha wajib pajak. Objek Pajak yang termasuk dalam katagori sistem online pajak daerah adalah yang pemungutannya bersifat self-assessment sytem yaitu wajib pajak yang melaporkan pajaknya langsung. Wajib pajak yang termasuk dalam jenis ini antara lain yaitu pajak hotel, pahak restoran, pajak hiburan dan pajak parkir.

Adapun Tata Cara Sistem Online Pajak Daerah dilihat dari ruang lingkupnya. Sistem Online pembayaran dan penyetoran dilakukan didinas dengan bank presepsi yang ditunjuk meliputi pemindah bukuan hal penerimaan pembayarn pajak secara elektronik dari wajib pajak ke rekening Kas Daerah. Sistem Online SPTPD dimana pelaporan ini disebut denga sistem pelaporan e-TAX yaitu pelaporan melalui web Badan Pendapatan dengan setiap bulannya. Sistem Online Pajak Daerah juga terdapat Sistem Online data transaksi usaha wajib pajak dimana sistem ini merupakan perekam terhadap data transaksi usaha pada wajib pajak. sitem alat perekam monitoring ini ada 3 (tiga) yaitu, Tapping Box, Web Sercive dan Cash Register Online. Adapun sanksi bagi wajib pajak yang melanggrar peraturan Sistem Online Pajak Daerah yaitu adanya sanksi Adimistratif dan ketentuan Pidana.

Dari hasil wawancara tersebut dan data yang didapatkan di Badan Pendapatan/ Pasedahan Agung dapat dikatakan Sistem Online Pajak Daerah pelaksanaannya efektif dilihat pada tahun 2016 jumlah wajib pajak 3730, wajib pajak manual 2404, wajib pajak online 1326 dan presentasenya $35.55 \%$. pada tahun 2017 jumlah wajib pajak 4307, wajib pajak manual 2443, wajib pajak online 1864, dan prsentasenya $43,28 \%$. Pada umumnya setiap tahun adanya pengingkatan dalam peloporan pajak secara online pada tahun 2018 jumlah wajib pajak 4393, wajib pajak manual 2482, wajib pajak online 1911, dan presentasenya $43.50 \%$. untuk alat perekam monitoring transaksi usaha pada wajib pajak dapat dikatanya berjalan secara baik/ efektif dilihat dari selama 2013-2017 kenaikan sebanyak 50\% sehingga rata-rata kenaikan tiap tahun $7 \%$. Dengan adanya sistem online pajak daerah juga dapat meningkatkan sector Pajak dalam PAD saat ini 50\%.

Dalam pelaksanaan Sistem Online Pajak Daerah adapun hambatan-hambatan dapat dilihat dari faktor kendala yurisdis yaitu Peraturan Daerah Kabupaten Badung Nomor 2 Tahun 2016 dimana pelaksanaan sistem online pajak daerah dimana pada pasal 12 tercantum untuk pemasangan alat perekam monitoring transaksi usaha pada wajib pajak. Adanya wajib pajak yang masih menolak dipasangkanya alat dengan alasan kurangnya pengetahuan wajib pajak dalam penggunakan teknologi informasi dan dengan alasan ketidak cocokan sistem pada wajib pajak dengan sistem badan pendapatan kabupaten badung. Selain adanya faktor kendala yuridis ada juga faktor non yuridis seperti infrastruktur jaringan yang tidak mendukung dan faktor SDM yaitu yang kurangnya pengetahuan tentang teknologi informasi dan masih adanya celah wajib pajak dapat melaporkan pajaknya secara online tetapi belom tentu melaporkan dengan nilai pajak yang sesungguhnya.

\section{SIMPULAN DAN SARAN Simpulan}

Badan Pendapatan Daerah/Pasedahan Agung Kabupaten Badung selaku pangelola pendapatan, memiliki tujuan pokok yakni Peningkatan Asli Daerah (PAD) Kabupaten Badung. Dalam melaksanakan pajak daerah Badan Pendapatan berdasarkan peraturan perundang-undangan dan 
otonomi daerah. Badan Pendapatan Daerah/Pasedahan Agung berinovasi melaksanakan Sistem Online Pajak Daerah untuk meningkatkan pelayanan publik dan penyelenggaran pemerintahan berjalan secara efektif dan efisien. Objek pajak yang termasuk dalam Sistem Online Pajak Daerah yaitu wajib pajak seperti pajak hotel, pajak restaurant, pajak hiburan dan Pajak Parker. Tata cara pelaksanan Sistem Online Pajak Daerah yaitu adanya Sistem pelaporan pajak secara online melalui web badan pendapatn yang disebut dengan sistem e-Tax dan adanya sistem Pemasangan alat perekam monitoring transaksi usaha pada wajib pajak untuk mengurangi tingkatnya keocoran dan kecuran pada wajib pajak.

Kemudian, sistem Online Pajak Daerah dapat dikatan efektif yaitu diliahat dari tahun 2016-2018, pajak hotel yang mengunakan sistem online berjumlah 3039 rata-rata pertahun sebanya 1013 pengguna. Pajak restaurant sejumlah 1562 dengan rata-rata pertahun 154 pengunana. Pajak hiburan sejumlah 462 dengan rata-rata pertahun 154 pengguna. Pajak parkir pada tahun 2016-2017 sebesar 4 pengguna, sedangkan tahun 2017-2018 tidak mengalami pertumbuhan yaitu tetap pada 14 Pengguna sistem online dimana rata-rata pertahub sebanyak 13 . Adapun peningkatan pemasangan alat pereka monitoring transaksi usaha pada wajib pajak selama 2013-2017 kenaikan sebanyak 50\% sehingga setiap tahuan 7\% dan adanya peningkatan pajak PAD (Pendapatan Asli Daerah)yang sampai saat ini peningktan sebesar $50 \%$. Dapun faktor-faktor yang timbul setelah dilaksanakan Sistem Online Pajak Daerah seperti faktor kendala yuridis maupun fator kendala non yuridis.

\section{Saran}

Dengan adanya sistem online ini, diharapkan dapat meningkatkan efisiensi dan efektivitas dari sisi wajib pajak maupun aparat birokrasi Badan Pendapatan Daerah/ Pasedahan Agung Kabupaten Badung kewenangan pengelolaan dan tata cara pelaksanaan sistem Online Pajak Daerah. Kemudian, diharapkan kepada pemerintah untuk meningkatan sosialisasi dan memberikan pemahaman ke masyarakat tentang Sistem Online Pajak Daerab kepada Wajib Pajak. Serta sistem pemungutan pajak secara selfassessment, pelaporan Surat Pemberitahuan Pajak Daerah secara online tidak menutup kemungkinan masih adanya celah dimana wajib pajak dapat melaporkan pajaknya secara online tetapi belum tentu melaporkan dengan nilai pajak yang sesungguhnya dengan itu diharapkan Badan Pendapatan Daerah/ Pasedahan Agung Kabupaten Badung perlu meningkatkan upaya melakukan pelaksanaan tindakantindakan tegas yang diatur dalam peraturan perundang-undangan bagi Wajib Pajak yang melaporkan pajaknya tidak sesuai dengan nilai pajak yang sesungguhnya.

\section{DAFTAR PUSTAKA}

Ali, Z. (2015). Metode Penelitian Hukum (6th ed.). Jakarta: Sinar Grafika.

Bambang, S. (2009). Metode Penelitian Hukum. Jakarta: PT. Raja Grafindo Persada.

Kaho, R. (1982). Analisa Hubungan Pemerintah Pusat dan Daerah di Indonesia. Jakarta: Bina Aksara.

Leliya, \& Afiyah, F. (2016). Efektivitas Sistem Pembayaran Pajak Daerah Online dalam Peningkatan Pendapatan Daerah Kota Cirebon. Jurnal AL-Mustashfa, 4(2), 158-177.

Munawir, H. S. (1997). Perpajakan. Yogyakarta: Liberty.

Puspitasari, P. I., \& Sumerthayasa, P. G. A. (2017). Penerapan Sistem Online dalam Pembayaran Pajak Hotel pada Dinas Pendapatan Daerah Kabupaten Badung. Kertha Negara: Journal Ilmu Hukum, 5(2), 1-12.

Undang-Undang Nomor 28 Tahun2007 tentang Ketentuan Umum dan Tata Cara Perpajakan

Peraturan Daerah Kabupaten Badung Nomor 2 Tahun 2016 tentang Sistem Online Pajak Daerah 